\title{
Feeling matters: Perceived Social Support Moderate the Relationship between Personal Relative Deprivation and Depressive Symptoms
}

Sibo Zhao ( $\nabla$ sibozhao@cufe.edu.cn )

Central University of Finance and Economics https://orcid.org/0000-0002-2828-5007

Li Peng

Central University of Finance and Economics

Research article

Keywords: China, Personal Relative Deprivation, Depressive Symptoms, Perceived Social Support

Posted Date: April 27th, 2021

DOI: https://doi.org/10.21203/rs.3.rs-461250/v1

License: () (7) This work is licensed under a Creative Commons Attribution 4.0 International License. Read Full License

Version of Record: A version of this preprint was published at BMC Psychiatry on July 12th, 2021. See the published version at https://doi.org/10.1186/s12888-021-03334-8. 


\section{Abstract}

Background Little research describes the mechanisms underlying depressive symptoms and personal relative deprivation in Chinese populations.

Methods In this study, the respondents were $(N=938)$ residents of Beijing (17-59 years old) and robust multiple linear regressions were used to assess the main relationship between relative deprivation and depressive symptoms and social support as a potential moderator for that relationship.

Results Individuals who reported higher personal relative deprivation had greater depressive symptoms than those who reported lower personal relative deprivation. Perceived social support buffered the relationship between depressive symptoms and personal relative deprivation.

Conclusions The findings of this current study demonstrate the importance of relative deprivation for psychological strain and income in explaining how socioeconomic indices correlate with depressive symptoms. They also demonstrate the need to acknowledge the interaction of perceived social support and personal relative deprivation for influencing depression.

\section{Background}

Depressive symptoms are usually regarded as negative emotional experiences such as those which might ensue after a series of negative life events. Mounting evidence indicates that depressive symptoms are associated with increased and prolonged psychological crises and health-risky behavior, and one of their most extreme consequences is suicide [1, 2]. The global prevalence of depression (lifetime prevalence of depression without comorbid anxiety disorder) is about $5.3 \%$ [3], and the prevalence of depression in mainland China is about $6.8 \%$ [4].

A number of researchers have taken depressive symptoms as an outcome of health inequality $[5,6]$, and relative deprivation has been used as an indicator of such inequality or a predictor of mental health in a variety of studies $[7,8]$. The theoretical framework of relative deprivation, which was originally elaborated by WG Runciman [9]), indicated that relative deprivation derives from a comparison of one's own economic status that of others to find that the comparer is worse off. The Relative Deprivation Hypothesis suggests that inequality motivates individual-level socioeconomic comparisons, and these lead to worsened social relations, greater stress, and resulting poorer mental health and well-being, including depressive symptoms (reviewed in Wilkinson and Pickett 2006, 2009; Pickett and Wilkinson 2015). Nevertheless, though substantial evidence has supported the relative deprivation hypothesis, it remains controversial concerning the appropriate measurements of individual relative deprivation and the understanding of the subsequent contradictory results.

One controversy is about the measurements of relative deprivation. Many previous studies have used one economic measure instead of comprehensive measure to assess relative deprivation. Specifically, some have focused on the magnitude of income difference, while others were concerned about income rank. For example, researchers have taken a measure of relative income with reference to a mean income level of an individual, state, or country [13, 14], or developed a variety of indexes (e.g., the Yitzhaki Index, the Podder Index, the Carstairs Index, and the Townsend Index), which usually incorporated a few broader social factors, such as unemployment rate, to quantify the income inequality in comparison to the broader population (reviewed in Morris and Carstairs 1991; Eibner, et al., 2004; Adjaye-Gbewonyo and Kawachi 2012). However, the findings on mental health and relative deprivation of income yield inconsistent results due to the use of different measures and the selection of different reference groups [17]. Consequently, a new line of subsequent psychosocial researches has focused on the relationship between mental health and income ranking, indicating that the income rank alone constitutes a better proxy variable for relative deprivation on psychosociology [18-20]. Yet, despite the concept of relative deprivation from an economic perspective is well known, personal relative deprivation is also considered to be a psychological consequence of inequality. This consequence is based not only on single item comparisons like income or social status but multidimensional comparisons as well (including personal competence, income, and place on the social ladder). Thus, the specific operationalized measurement of relative deprivation would differ across cultural context [21]. For example, since the 1980s, economic reforms in China have caused important changes in urban and rural families, which are closely related to personal relative deprivation in different ways [22]. Therefore, in this study, we will not only measure the relative deprivation concerning individual characteristics like income, competence and social status, but also use a comprehensive measurement, taking family background into account.

Another controversy is that whether objective status of relative deprivation can reflect the subjective feeling of being deprived. Subjective feeing is about an individual's own sense of life-time achievement and socioeconomic status, which may be misaligned with objective indicators. For example, MK Whyte [23]) pointed out that compared to people in other countries, people in China responded to the inequality with a more positive attitude, and the negative feeling about inequality was less than expectation in spite of the increasing aggravation of social inequality after the economic reforms. On this basis, some researchers paid more attention to the individual-level subjective perception of inequality, and examined the association between that and poorer mental and physical health $[24,25]$. For example, Demakakos and colleagues [26] found that subjective social status significantly predicted a number of health-related outcomes in old age, including depression. Zhang and colleagues, using their Psychological Strain Scale (PSS), posited four types of strains that predict mental health outcomes (including anxiety, depression, and suicidal ideation), one of which is relative deprivation strain, measured with a 10-item scale that assesses perceived differences between the respondent's own status and the perceived status of others [27]. Hence, we will consider both objective and subjective relative deprivation in this study, and focus far more on exploring the effect of subjective relative deprivation on mental health.

Only a handful of empirical papers have examined subjective feelings of relative deprivation and depressive symptoms (Beshai, et al., 2017; Mishra and Carleton 2015), and there are still few studies that have used both single and comprehensive measures to assess personal relative depravation. Relative income deprivation measures a single aspect of social inequality, while a multidimensional comparison of relative deprivation assesses a range of aspects of a person's life and is more likely to vary in different personal scenarios. It is therefore possible that the association between a single measure of personal relative deprivation and depressive symptoms is different from the association between comprehensive measures and depressive symptoms, especially after absolute personal income is controlled for. Therefore, the first attempt of this study is to compare the effect of single and comprehensive measure of personal relative deprivation on depressive symptoms. 
Perceived social support is an influential force buffering the relationship between psychosocial stress and mental health, that individual perceived via one's social network to protect one from negative events or improve one's well-being [28]. Unfortunately, few recent studies have examined how perceived social support contribute to mechanisms underlying the relationship between personal relative deprivation and depressive symptoms. Previous studies were found that perceived social support is negatively related to depressive symptoms $[29,30]$. College students with lower levels of social support have been found to be more likely to exhibit high levels of depression, which may also increase the risk for suicidal behavior [31, 32]. Social support is also considered as moderating variable that explains the relationship between the two variables. Zhang and Lin [33] found that social support serves a moderating function in suicides of rural youth in China, such that high social support had a protective effect for individuals with low impulsivity. In this circumstance, social support might help to buffer the shock of personal relative deprivation to mental health, and specifically, help to buffer depressive symptoms related to personal relative deprivation.

The limited evidence suggests that personal relative deprivation is associated with poorer mental health. We investigated the relationships between personal relative deprivation, social support, and depressive symptoms in a more comprehensive manner. In this study, we propose a conceptual model to describe the moderation exerted by the intermediary variable of social support on the relationship between personal relative deprivation and depressive symptoms. This study examines the following research hypotheses, grounded in the literature: (1) increased personal relative deprivation level is positively associated with increased depressive symptoms, and social support level is negatively associated with depressive symptoms; (2) perceived social support moderates the relationship between depressive symptoms and relative deprivation in income and relative deprivation in psychological strain.

\section{Methods}

\subsection{Sampling and procedure}

The data for the current study were obtained from questionnaires distributed among residents of Beijing in 2017 . The survey was conducted by the Questionnaire Star, a professional online survey company. The Principal Investigator signed a contract with the Questionnaire Star to specify the cost of the survey and how the responses would be kept confidential. The respondents were current residents of Beijing aged from 17 to 59 . The quality control methods undertaken were as follows:

(1) the questionnaire was only distributed to users who meet selection requirements;

(2) screening items were set to verify that participants met the sample qualifications;

(3) online systems were used to monitor the process; these took account of the IP addresses, tracked which electronic devices were used, and administered trap items, time limits, and sampling procedures;

(4) after the completion of all questionnaires, a quality check was performed to assess the completeness, formatting, and effectiveness of each of the data records.

A total of 950 responses were investigated, and 12 were eliminated due to incompletion, giving a completion rate of $98.7 \%$.

\subsection{Ethical approval}

The research protocol of the study was formally approved by the Institutional Review Board of the Ethics Committee at the University where the Principal Investigator is affiliated. All participants provided written informed consent prior to completing the study self-report instruments and did not provide identifying information on any of the questionnaires.

\subsection{Measurements}

\subsubsection{Outcome (Depression)}

The Center for Epidemiologic Studies Depression Scale (CES-D) was used to evaluate depressive symptoms (Radloff 1977). This self-report scale includes 20 items, each assessed on an 8-point Likert-type scale, with responses ranging from 0 to 7, representing how many days the participants have experienced depressive symptoms over the past week. Consistently with previous studies, this 8 -point scale was re-coded into a 4 -point scale, as follows: $0=0$ days, $1=1-$ 2 days, $2=3-4$ days, and $3=5-7$ days. The total points for all items (ranging from 0 to 60 ) was computed to indicate the level of depression. The four inverted items in the scale (items $4,8,15$, and 20 ) were reversed before the tally. The good internal consistency of the scale for this sample was confirmed with Cronbach's alpha $(a=0.9311)$.

\subsubsection{Indicator (Relative Deprivation)}

Relative Deprivation in Psychological Strain. A slightly modified version of the relative deprivation subscale of the PSS was used to evaluate the level of relative deprivation (Zhang, et al., 2014). For this, the respondents were asked to assess ten statements regarding situations they experienced in their lives, such as "Compared to other families in my community, my family is poor," and "I believe I am good enough, but am dissatisfied with treatment from others." Subjects rate their responses on the following five-point scale: $1=$ never, $2=$ rarely, $3=$ maybe, $4=$ often, and $5=$ yes. The total score (ranging from 10 to 50 ) indicates the level of psychological strain due to relative deprivation, with higher scores associated with higher relative deprivation. The Cronbach's alpha coefficient for the PSS subscale was $a=0.923$. 
Relative income deprivation. We designed a four-item instrument to assess respondents' perceptions of relative lack of income compared to four groups as their references: friends, colleagues, occupation peers, and significant others. Each item was rated on a 5-point Likert-type scale: $1=$ not at all satisfied, $2=$ not very satisfied, 3 = generally satisfied, $4=$ somewhat satisfied, and $5=$ completely satisfied. The points were reverse coded, and the total score (ranging from 4 to 20 ) was used for analysis. Higher the scores indicated higher relative deprivation. The Cronbach's alpha coefficient for this scale was a $=0.806$.

\subsubsection{Potential Moderator (Perceived Social Support)}

The Multidimensional Scale of Perceived Social Support (MSPSS) was used to measure social support (Zimet, et al., 1988). The Chinese 12-item version of the scale has been tested and found to have sound validity and reliability among Chinese adolescents (Chou 2000). The answers ranged from $1=$ strongly disagree to 7 = strongly agree. The total score (ranging from 12 to 84 ) was analyzed in the present study. High internal consistency was found (Cronbach's a = 0.9425).

\subsubsection{Control Variables}

Sex was assessed as a binary variable, with $1=$ male and $0=$ female. Age was computed by subtracting the date of birth from July 2017 . Marital status was coded as 0 = others (including cohabitation, separated but not divorced, divorced, and widowed), 1 = single, or $2=$ married (including married and remarried). Education was coded as $0=$ college degree and below (including no formal education, elementary school, middle school, vocational high school, high school, technical secondary school, technical school, and college) or $1=$ bachelor's degree and above (including university completion, graduate degree, and above). Occupation type was converted to match the International Socioeconomic Index (ISEI), a general measure that evaluates the conversion capacity of occupations in terms of the substitutability of human resources and the potential payoff, where higher ISEl scores indicate higher socioeconomic status (Ganzeboom, de Graaf, \& Treiman, 1992). Monthly personal income was transformed to a logarithmic scale and controlled for in the model. Location of origin was a binary variable, with 1 indicating those from urban China and 0 indicating those from rural China.

\subsection{Analysis}

All data were analyzed with STATA 16.0. Major variables for study were compared across gender distributions. For all continuous variables, t-tests were performed, and chi-square tests were performed for non-continuous variables. Pearson's correlation was computed to examine the relationship between variables.

Robust multiple linear regressions were performed using the iteratively reweighted least square (IRLS) method to examine the associations between the dependent variable and the explanatory variables. IRLS does not impose an assumption of a normal distribution in a sample but instead assigns an analysis weight that is yielded from an iterative algorithm for each observation to deal with heteroscedasticity in the sample, meaning that the estimation is more effective and robust than the ordinary least square (OLS) model.

\section{Results}

\subsection{Description of demographic characteristics}

The sample contains 938 observations of Beijing residents who completed the entire questionnaire. Table 1 illustrates the respondents' socio-demographic characteristics by sex. Ages ranged from 17 to 59 years, and $51.81 \%$ of respondents were male.

The t-test or the chi-square test was used to test the significance of the difference in genders in CES-D scores (depressive symptoms), relative deprivation scores in psychological strain and income, MSPSS scores (social support), and other variables for the study. The female respondents reported lower relative deprivation scores in psychological strain and income, and they also had lower monthly income than male respondents. Females also reported higher scores for social support and ISEl index than males did. Among the 938 respondents, $67.48 \%$ were married and $24.41 \%$ were single. There were no significant differences in marital status between male and female, $p>0.05$. More than half of respondents had an educational level of college or below (53.41\% vs. $46.59 \%$ ), and females tended to hold a higher diploma on average. More respondents were from urban than rural areas (84.22\% vs. $15.78 \%)$, which is consistent with the distribution of population in Beijing overall. There was no significant difference between males and females in residence location.

\subsection{Correlation analysis}

We performed correlation analysis between depressive symptoms and other major variables. Pearson's correlation coefficients and the Sidak-adjusted significant level of counterparts are shown in Table 2. In the correlation matrix it can be seen that depressive symptoms were significantly positively associated with relative deprivation in psychological strain $(r=0.529, p<0.001)$ and significantly negatively associated with social support $(r=-0.491, p<$ $0.001)$. Additionally, depressive symptoms had a weakly positive correlation with relative deprivation in income $(r=0.233, p<0.001)$. Furthermore, respondents with greater social support scores tended to have lower scores for relative deprivation in psychological strain $(r=-0.321, p<0.001)$ and lower CES-D scores $(r$ $=-0.491, p<0.001$ ), indicating a potential interaction mechanism between social support and relative deprivation in psychological strain.

\subsection{Robust regression model}

Administration of the Breusch-Pagan test showed a skew distribution for the dependent variable, indicating the possibility of a biased estimate with OLS regression. Hence, we used robust multiple linear regressions with IRLS.

Table 3 presents the results of the multiple regression models. Model 1 showed statistically significance $(F(12,924)=18.5, p<0.001)$ with an adjusted coefficient of determination $\mathrm{R}^{2}$ adj $=0.167$. Controlling for other variables, increased relative deprivation in income was statistically significantly associated with 
an increased score for depressive symptoms ( $<$ < 0.001), and the absolute income was negatively associated with depressive symptoms $(p<0.001)$. In addition, respondents from urban areas reported lower depressive symptoms than respondents from rural areas $(p<0.001)$, and respondents who were single or married reported lower depressive symptoms than people with other marital status $(p<0.001)$. However, no evidence was found to support significance of effects of age, sex, education level, or ISEl on depressive symptoms in Model 1.

In Model 2, we included perceived social support and its interaction items with income relative deprivation to assess the hypothesis of moderation. After other variables were controlled, it was found that perceived social support and its interaction item with income relative deprivation were negatively related to depressive symptoms, and both of these were statistically significant $(p<0.001)$.

We added relative deprivation in psychological strain to Model 3 to determine whether the association between a single measure of relative deprivation and depressive symptoms is different than that between a comprehensive measure and depressive symptoms. It was found that, after controlling for other variables, relative deprivation in psychological strain had a positive association with depressive symptoms, and perceived support had a negative association with depressive symptoms. Both relationships were statistically significant $(p<0.001)$. However, neither single measure, namely, relative deprivation in income or absolute income, was statistically significant. In addition, higher depressive symptoms were observed among respondents aged 17-29 years ( $p<0.001)$ than in the reference group (aged 40-59 years); the difference in depressive symptoms between those aged 30-39 years and the reference group were nonsignificant $(p=0.130)$.

In Model 4, we assessed the interactions between relative deprivation in psychological strain and perceived social support to test whether the effect of relative deprivation in psychological strain on depressive symptoms was moderated by social support. The result for the interaction term was statistically significant, indicating that perceived social support did reduce the marginal predictive effect of relative deprivation in psychological strain on depressive symptoms $(p=$ 0.014). However, the association between relative deprivation in income and depressive symptoms was not found to be statistically significant after controlling for other variables.

\section{Discussion}

We explored the association between personal relative deprivation, perceived social support, and depressive symptoms in China. We were particularly interested in testing whether perceived social support buffers the relationship between depressive symptoms and personal relative deprivation, with both single and comprehensive measures of personal relative deprivation. We found that individuals who reported higher personal relative deprivation had higher depressive symptoms than those who reported lower personal relative deprivation. Further, perceived social support had a negative association with depressive symptoms, providing supporting evidence for the first hypothesis. These results were consistent with those of previous research.

To explore heterogeneity among individuals further, we added two interactions between perceived social support and two types of personal relative deprivations to our models. These models provide qualified support for our second hypothesis. Our Model 2 showed that the positive direct effect of relative deprivation in income was buffered by perceived social support. Our Model 4 indicated that the positive direct effect of relative deprivation in psychological strain was statistically significant even with a significant interaction term in the model, indicating that individuals with a relative deprivation in psychological strain and perceived lower social support had a higher risk of depressive symptoms than those who perceived higher social support.

These results constitute new evidence for the association between personal relative deprivation and depressive symptoms. First, our findings support a significant positive association between personal relative deprivation and depressive symptoms and highlighted the use of comprehensive measures of subjective relative deprivation. Assuming that relative deprivation in income is a better predictor, we would expect an increase in relative deprivation in income to be associated with an increase in depressive symptoms even after controlling for other variables. We did not find a significant association between objective socioeconomic status (measured by ISEI) and depressive symptoms, in contrast with previous work (Nishimura, 2011). One possible reason for this is that there was little variance across occupation type in this sample because the participants were from several similar industries. Thus, using only objective socioeconomic indices might not be efficient for finding the association between socioeconomic status and depressive symptoms among individuals in the same or similar industries.

Second, although an increase in personal relative deprivation was generally associated with an increase in depressive symptoms, the positive effects of relative deprivation in income (Fig. 1) and relative deprivation in psychological strain (Fig. 2) were buffered by perceived social support (models 2 and 4). This indicates that not all individuals who experience personal relative deprivation are necessarily depressed but rather that there is a diversity of experience depending on the buffering effects of perceived social support. Cohen and Wills found that social support operates in such a way that perceived social support helps reduce stress assessment in stressful situations, alleviating the psychological trauma caused by stressful events (Cohen \& Wills, 1985). Consistent with the buffering hypothesis, perceived social support serves as a moderator, absorbing part of the relative deprivation strain and protecting against depressive symptoms.

\section{Limitations And Future Research Directions}

This study has some limitations that can provide directions for future research. Its major limitation is its use of a cross-sectional design, which allows statistical moderation to be identified but does not provide definitive evidence on whether the assumed cause precedes the assumed effect or whether the relationship is caused by a third factor. Thus, findings of this study provide only preliminary evidence of the moderation mechanism, such that the relationship between depressive symptoms and personal relative deprivation could be moderated by perceived social support. Future studies could further substantiate the relationship of a comprehensive measure of subjective personal relative deprivation with depressive symptomology and examine exactly which sub-

Page 5/11 
constructs of social support drive the buffering effect for the above relationship. This would be an important contribution to the literature on inequality and mental health. Additionally, the current sample is not representative of the general population, being younger, more educated, and more urban. Our recruitment strategy thus limited the generalizability of our results. Future work should investigate the effects of personal relative deprivation in a larger sample and examine the role of other variables (such as self-esteem) in the relationship between personal relative deprivation and depressive symptoms.

\section{Conclusions}

The findings of this study demonstrate the importance of relative deprivation for psychological strain and income in explaining how socioeconomic indices correlate with depressive symptoms. The results of this study also indicate the need to acknowledge the interaction between perceived social support and personal relative deprivation in influencing depression. This research provides several implications in this regard: first, psychological counselors and social workers should pay closer attention to depressed individuals who experience more relative deprivation in perceived social support and use multiple methods, including group counseling, to help people who meet this profile buffer the stress from psychological strain to reduce their depressive symptoms; second, social and political action are imminently necessary to reduce inequality in China, as it is important to allocate wealth impartially to improve support wellbeing and mental health.

\section{Abbreviations}

\section{PSS}

Psychological Strain Scale

CES-D

The Center for Epidemiologic Studies Depression Scale

MSPSS

The Multidimensional Scale of Perceived Social Support

ISEI

The International Socioeconomic Index

IRLS

The iteratively reweighted least square

OLS

The ordinary least square

\section{Declarations}

\section{Ethics approval and consent to participate}

All procedures performed in studies involving human participants were in accordance with the ethical standards of the institutional research committee and with the 1964 Helsinki Declaration. The study protocol was approved by the Ethics Committee of Central University of Finance and Economics.

The written informed consents were obtained from all participants before they enrolled in this study.

\section{Consent for publication}

Not applicable

\section{Availability of data and materials}

The datasets used and/or analyzed during the current study are available from the corresponding author on reasonable request.

\section{Competing interests}

The authors have no conflict of interest to disclose.

\section{Funding}

Funding for this study was provided by Beijing Social Science Fund (No. 19SRC013). Beijing Social Science Fund had no role in the study design, collection, analysis or interpretation of the data, writing the manuscript, or the decision to submit the paper for publication.

\section{Authors' contributions}

LP conducted the statistical analysis. SZ conducted literature searches and provided summaries of previous research studies and all authors contributed to and have approved the final manuscript.

\section{Acknowledgements}

We thank LetPub (www.letpub.com) for its linguistic assistance during the preparation of this manuscript.

\section{References}


1. Kisch J, Leino EV, Silverman MM: Aspects of suicidal behavior, depression, and treatment in college students: Results from the Spring 2000 National College Health Assessment Survey. Suicide and Life-Threatening Behavior 2005, 35(1):3-13.

2. Zhang J, Tao M. Relative deprivation and psychopathology of Chinese college students. J Affect Disord. 2013;150(3):903-7.

3. Fiona C, van Ommeren M, Flaxman A, Cornett J, Whiteford H, Saxena S. New WHO prevalence estimates of mental disorders in conflict settings: a systematic review and meta-analysis. The Lancet. 2019;394(10194):240-8.

4. Huang Y, Wang Y, Wang H, Liu Z, Yu X, Yan J, Yu Y, Kou C, Xu X, Lu J, et al. Prevalence of mental disorders in China: a cross-sectional epidemiological study. The Lancet Psychiatry. 2019;6(3):211-24.

5. Dong $\mathrm{X}, \mathrm{Ng} \mathrm{N}$. Contribution of multiple pathways to the relationship between visual impairment and depression: Explaining mental health inequalities among older Chinese adults. J Affect Disord. 2021;278:350-6.

6. Cabezas-Rodríguez A, Bacigalupe A, Martín U. Diagnosis and Treatment of Depression in Spain: Are There Gender Inequalities? International Journal of Environmental Research Public Health. 2020;17(24):9232.

7. Callan MJ, Kim H, Matthews WJ. Predicting self-rated mental and physical health: The contributions of subjective socioeconomic status and personal relative deprivation. Frontiers in psychology. 2015;6:1415.

8. Eibner C, Sturm R, Gresenz CR. Does Relative Deprivation Predict the Need for Mental Health Services? Journal of Mental Health Policy Economics. 2004;7(4):167-75.

9. Runciman WG. Relative deprivation and social justice: A study of attitudes to social inequality in twentieth-century England. University of California Press Berkeley; 1966.

10. Wilkinson RG, Pickett KE. Income inequality and social dysfunction. Annual review of sociology. 2009;35:493-511.

11. Wilkinson RG, Pickett KE. Income inequality and population health: a review and explanation of the evidence. Soc Sci Med. 2006;62(7):1768-84.

12. Pickett KE, Wilkinson RG. Income inequality and health: a causal review. Soc Sci Med. 2015;128:316-26.

13. Wilkinson RG, Pickett KE. The problems of relative deprivation: why some societies do better than others. Soc Sci Med. 2007;65(9):1965-78.

14. Yngwe M, Fritzell J, Lundberg O, Diderichsen F, Burström B. Exploring relative deprivation: is social comparison a mechanism in the relation between income and health? Soc Sci Med. 2003;57(8):1463-73.

15. Morris R, Carstairs V. Which deprivation? A comparison of selected deprivation indexes. J Public Health. 1991;13(4):318-26.

16. Adjaye-Gbewonyo K, Kawachi I. Use of the Yitzhaki Index as a test of relative deprivation for health outcomes: a review of recent literature. Soc Sci Med. 2012;75(1):129-37.

17. Hounkpatin HO, Wood AM, Dunn G. Does income relate to health due to psychosocial or material factors? Consistent support for the psychosocial hypothesis requires operationalization with income rank not the Yitzhaki Index. Soc Sci Med. 2016;150:76-84.

18. Daly M, Boyce C, Wood A. A social rank explanation of how money influences health. Health Psychol. 2015;34(3):222.

19. Hounkpatin HO, Wood AM, Brown GD, Dunn G. Why does income relate to depressive symptoms? Testing the income rank hypothesis longitudinally. Soc Indic Res. 2015;124(2):637-55.

20. Wood AM, Boyce CJ, Moore SC, Brown GD. An evolutionary based social rank explanation of why low income predicts mental distress: A 17 year cohort study of 30,000 people. J Affect Disord. 2012;136(3):882-8.

21. Ellemers N. Social identity and relative deprivation. In: Relative deprivation: Specification, development, and integration. Cambridge University Press; 2002. pp. 239-64.

22. Li C. The Changing Trend of Educational Inequality in China(1940-2010):Reexamining the Urban-rural Gap on Educational Opportunity. Sociological Studies. 2014;02:65-89+243.

23. Whyte MK. Views of Chinese Citizens on Current Inequalities. Sociological Studies. 2009;1:96-120 + 244.

24. Beshai S, Mishra S, Meadows TJ, Parmar P, Huang V. Minding the gap: Subjective relative deprivation and depressive symptoms. Soc Sci Med. 2017;173:18-25.

25. Mishra S, Carleton RN. Subjective relative deprivation is associated with poorer physical and mental health. Soc Sci Med. 2015;147:144-9.

26. Demakakos P, Nazroo J, Breeze E, Marmot M. Socioeconomic status and health: the role of subjective social status. Soc Sci Med. 2008;67(2):330-40.

27. Zhang J, Lu J, Zhao S, Lamis DA, Li N, Kong Y, Jia C, Zhou L, Ma Z. Developing the Psychological Strain Scales (PSS): Reliability, Validity, and Preliminary Hypothesis Tests. Soc Indic Res. 2014;115(1):337-61.

28. Chou KL. Assessing Chinese adolescents' social support: The Multidimensional Scale of Perceived Social Support. Personality Individ Differ. 2000;28:299-307.

29. Cohen S, Wills TA. Stress, social support, and the buffering hypothesis. Psychol Bull. 1985;98(2):310-57.

30. Lin N, Ye S, Ensel WM. Social Support and Depressed Mood: A Structural Analysis. J Health Soc Behav. 1999;40:344-59.

31. Zhang J, Liu Y, Sha L. The Use of Microblog, Social Support, and Depression: A Study of Chinese College Students. International Journal of School Cognitive Psychology. 2016;3(1):1-5.

32. Zhao S, Zhang J. The association between depression, suicidal ideation and psychological strains in college students: a cross-national study. Culture Medicine Psychiatry. 2018;42(4):914-28.

33. Zhang J, Lin L. The Moderating Effect of Social Support on the Relationship Between Impulsivity and Suicide in Rural China. Community Ment Health J. 2015;51(5):585-90. 
Table 1

Demographic descriptions for study variables and their sex comparison.

\begin{tabular}{|c|c|c|c|c|c|}
\hline Variable & $\begin{array}{l}\text { Total(n = 938) } \\
M \pm S D / f(\%)\end{array}$ & $\begin{array}{l}\text { Female }(n=452) \\
M \pm S D / f(\%)\end{array}$ & $\begin{array}{l}\text { Male }(n=486) \\
M \pm S D / f(\%)\end{array}$ & $t / x^{2}$ & $P$ \\
\hline Depression & $19.93 \pm 11.03$ & $19.49 \pm 10.22$ & $20.35 \pm 11.73$ & -1.198 & 0.231 \\
\hline Relative deprivation in psychological strain & $25.95 \pm 8.04$ & $25.28 \pm 8.10$ & $26.58 \pm 7.94$ & -2.481 & $0.013^{*}$ \\
\hline Social support & $61.78 \pm 10.13$ & $62.37 \pm 10.50$ & $61.23 \pm 9.76$ & 1.728 & 0.084 \\
\hline Relative deprivation in Income & $18.27 \pm 3.31$ & $18.04 \pm 3.46$ & $18.49 \pm 3.15$ & -2.078 & $0.038^{*}$ \\
\hline Ln(monthly-income) (RMB) & $9.05 \pm 0.52$ & $8.96 \pm 0.47$ & $9.13 \pm 0.54$ & -5.127 & $<0.001^{* * *}$ \\
\hline ISEI & $54.07 \pm 14.28$ & $55.37 \pm 13.04$ & $52.85 \pm 15.27$ & 2.690 & $0.006^{\star *}$ \\
\hline $\begin{array}{l}\text { Age } \\
17-29 \\
30-39 \\
40-59\end{array}$ & $\begin{array}{l}344(36.67) \\
417(44.46) \\
177(18.87)\end{array}$ & $\begin{array}{l}187(41.37) \\
211(46.68) \\
54(11.95)\end{array}$ & $\begin{array}{l}157(32.30) \\
206(42.39) \\
123(25.31)\end{array}$ & -5.352 & $<0.001^{\star \star \star}$ \\
\hline $\begin{array}{l}\text { Marital } \\
\text { Single } \\
\text { Married } \\
\text { Others }\end{array}$ & $\begin{array}{l}229(24.41) \\
633(67.48) \\
76(8.10)\end{array}$ & $\begin{array}{l}104(23.01) \\
319(70.58) \\
29(6.42)\end{array}$ & $\begin{array}{l}125(25.72) \\
314(64.61) \\
47(9.67)\end{array}$ & 5.003 & 0.082 \\
\hline $\begin{array}{l}\text { Education } \\
\text { College degree and below } \\
\text { Bachelor degree and above }\end{array}$ & $\begin{array}{l}501(53.41) \\
437(46.59)\end{array}$ & $\begin{array}{l}224(49.56) \\
228(50.44)\end{array}$ & $\begin{array}{l}277(57) \\
209(43)\end{array}$ & 5.207 & $0.022^{*}$ \\
\hline $\begin{array}{l}\text { Residence } \\
\text { Rural } \\
\text { Urban }\end{array}$ & $\begin{array}{l}148(15.78) \\
790(84.22)\end{array}$ & $\begin{array}{l}66(14.60) \\
386(85.40)\end{array}$ & $\begin{array}{l}82(16.87) \\
404(83.13)\end{array}$ & 0.909 & 0.340 \\
\hline
\end{tabular}

Table 2

Correlations among major study variables.

\begin{tabular}{|c|c|c|c|c|c|c|c|}
\hline Variables & Depression & $\begin{array}{l}\text { Relative deprivation in psychological } \\
\text { strain }\end{array}$ & $\begin{array}{l}\text { Social } \\
\text { support }\end{array}$ & $\begin{array}{l}\text { Relative } \\
\text { deprivation } \\
\text { in Income }\end{array}$ & $\begin{array}{l}\text { Ln(monthly- } \\
\text { income) }\end{array}$ & ISEI & Age \\
\hline Depression & 1 & & & & & & \\
\hline $\begin{array}{l}\text { Relative deprivation } \\
\text { in psychological } \\
\text { strain }\end{array}$ & $0.529^{\star * *}$ & 1 & & & & & \\
\hline Social support & $-0.491^{\star \star \star}$ & $-0.321^{\star \star \star}$ & 1 & & & & \\
\hline $\begin{array}{l}\text { Relative deprivation } \\
\text { in Income }\end{array}$ & $0.233^{\star \star \star}$ & $0.243^{\star \star \star}$ & $-0.456^{\star \star \star}$ & 1 & & & \\
\hline Ln(monthly-income) & $-0.208^{\star \star \star}$ & $-0.311^{\star \star \star}$ & $0.266^{\star \star \star}$ & $-0.122^{\star *}$ & 1 & & \\
\hline ISEI & -0.075 & $-0.154^{\star \star \star}$ & $0.162^{\star \star \star}$ & -0.065 & $0.332^{\star \star \star}$ & 1 & \\
\hline Age & -0.026 & 0.092 & $-0.113^{*}$ & $0.141^{\star \star *}$ & -0.079 & -0.077 & 1 \\
\hline
\end{tabular}


Table 3

Robust multiple regression for depressive symptoms.

\begin{tabular}{|c|c|c|c|c|c|c|c|c|c|c|c|c|}
\hline \multirow[t]{3}{*}{ Variable } & \multicolumn{12}{|l|}{ Depression } \\
\hline & \multicolumn{3}{|l|}{ Model 1} & \multicolumn{3}{|l|}{ Model 2} & \multicolumn{3}{|l|}{ Model 3} & \multicolumn{3}{|l|}{ Model 4} \\
\hline & $\beta$ (S.E.) & $t$ & $p$ & $\beta$ (S.E.) & $t$ & $\mathrm{p}$ & $\beta$ (S.E.) & $\mathbf{t}$ & $p$ & $\beta$ (S.E.) & $t$ & $p$ \\
\hline $\begin{array}{l}\text { Relative } \\
\text { deprivation in } \\
\text { psychological } \\
\text { strain }\end{array}$ & & & & & & & $\begin{array}{l}0.530 \\
(0.037)\end{array}$ & 14.24 & $\begin{array}{l}< \\
0.001\end{array}$ & $0.544(0.038)$ & 14.32 & $\begin{array}{l}< \\
0 . c\end{array}$ \\
\hline $\begin{array}{l}\text { Perceived social } \\
\text { support }\end{array}$ & & & & $-0.516(0.339)$ & -15.23 & $<.001$ & $\begin{array}{l}-0.420 \\
(0.032)\end{array}$ & -13.13 & $<.001$ & $\begin{array}{l}-0.410 \\
(0.033)\end{array}$ & -12.56 & $\begin{array}{l}< \\
0 . c\end{array}$ \\
\hline $\begin{array}{l}\text { Relative } \\
\text { deprivation in } \\
\text { income }\end{array}$ & $0.803(0.101)$ & 7.93 & $\begin{array}{l}< \\
0.001\end{array}$ & $0.172(0.099)$ & 1.74 & 0.082 & $\begin{array}{l}-0.039 \\
(0.093)\end{array}$ & -0.42 & 0.675 & $0.006(0.093)$ & 0.07 & $0 . \subseteq$ \\
\hline $\begin{array}{l}\text { Ln(monthly- } \\
\text { income) }\end{array}$ & $-3.706(0.720)$ & $-5,15$ & $<0.001$ & $-1.891(0.641)$ & -2.95 & 0.003 & $\begin{array}{l}-0.131 \\
(0.616)\end{array}$ & -0.21 & 0.832 & $\begin{array}{l}-0.221 \\
(0.615)\end{array}$ & -0.36 & $0 . \bar{i}$ \\
\hline ISEI & $0.025(0.022)$ & 1.17 & 0.241 & $0.021(0.019)$ & 1.12 & 0.262 & $\begin{array}{l}0.032 \\
(0.018)\end{array}$ & 1.79 & 0.074 & $0.031(0.018)$ & 1.72 & 0.1 \\
\hline $\begin{array}{l}\text { Sex } \\
\text { Male } \\
\text { Female } \\
\text { (reference) }\end{array}$ & $0.768(0.698)$ & 1.10 & 0.271 & $0.497(0.613)$ & 0.81 & 0.418 & $\begin{array}{l}-0.448 \\
(0.576)\end{array}$ & -0.78 & 0.438 & $-0.341(0.576)$ & -0.59 & $0 . \varepsilon^{t}$ \\
\hline $\begin{array}{l}\text { Age } \\
17-29 \\
30-39 \\
40- \\
59(\text { reference) }\end{array}$ & $\begin{array}{l}2.093(1.080) \\
0.541(0.943)\end{array}$ & $\begin{array}{l}1.94 \\
0.57\end{array}$ & $\begin{array}{l}0.053 \\
0.566\end{array}$ & $\begin{array}{l}2.796(0.952) \\
0.681(0.829)\end{array}$ & $\begin{array}{l}2.94 \\
0.82\end{array}$ & $\begin{array}{l}0.003 \\
0.411\end{array}$ & $\begin{array}{l}3.480 \\
(0.891) \\
1.175 \\
(0.776)\end{array}$ & $\begin{array}{l}3.90 \\
1.51\end{array}$ & $\begin{array}{l}< \\
0.001 \\
0.130\end{array}$ & $\begin{array}{l}3.495(0.888) \\
1.308(0.774)\end{array}$ & $\begin{array}{l}3.94 \\
1.69\end{array}$ & $\begin{array}{l}< \\
0 . c \\
0 . c\end{array}$ \\
\hline $\begin{array}{l}\text { Marital } \\
\text { Single } \\
\text { Married } \\
\text { Others(reference) }\end{array}$ & $\begin{array}{l}-5.628(1.349) \\
-4.789(1.256)\end{array}$ & $\begin{array}{l}-4.17 \\
-3.81\end{array}$ & $\begin{array}{l}< \\
0.001 \\
< \\
0.001\end{array}$ & $\begin{array}{l}-3.387(1.186) \\
-1.174(1.116)\end{array}$ & $\begin{array}{l}-2.86 \\
-1.05\end{array}$ & $\begin{array}{l}0.004 \\
< \\
0.001\end{array}$ & $\begin{array}{l}-4.517 \\
(1.110) \\
-2.082 \\
(1.042)\end{array}$ & $\begin{array}{l}-4.07 \\
-2.00\end{array}$ & $\begin{array}{l}< \\
0.001 \\
0.046\end{array}$ & $\begin{array}{l}-4.512 \\
(1.106) \\
-2.111 \\
(1.039)\end{array}$ & $\begin{array}{l}-4.08 \\
-2.03\end{array}$ & $\begin{array}{l}< \\
0 . c \\
0 . c\end{array}$ \\
\hline $\begin{array}{l}\text { Education } \\
\text { Bachelor degree } \\
\text { and above } \\
\text { College degree } \\
\text { and } \\
\text { below(reference) }\end{array}$ & $-0.846(0.695)$ & -1.22 & 0.224 & $-0.028(0.611)$ & -0.05 & 0.963 & $0.054(0.572)$ & 0.09 & 0.925 & $0.030(0.570)$ & 0.05 & $0 . \subseteq$ \\
\hline $\begin{array}{l}\text { Residence } \\
\text { Rural(reference) } \\
\text { Urban }\end{array}$ & $-5.723(0.934)$ & -3.81 & $<.001$ & $-4.227(0.823)$ & -5.13 & $<0.001$ & $\begin{array}{l}-3.373 \\
(0.772)\end{array}$ & -4.37 & $<.001$ & $\begin{array}{l}-3.297 \\
(0.769)\end{array}$ & -4.29 & $\begin{array}{l}< \\
0 . c\end{array}$ \\
\hline $\begin{array}{l}\text { Income Relative } \\
\text { deprivation \# } \\
\text { perceived social } \\
\text { support }\end{array}$ & & & & $-0.016(0.007)$ & -2.10 & 0.036 & & & & & & \\
\hline $\begin{array}{l}\text { Relative } \\
\text { deprivation in } \\
\text { Psychological } \\
\text { strain \# social } \\
\text { support }\end{array}$ & & & & & & & & & & $\begin{array}{l}-0.008 \\
(0.003)\end{array}$ & -2.46 & 0.1 \\
\hline Constant & $44.818(6.587)$ & 6.80 & $\begin{array}{l}< \\
0.001\end{array}$ & $38.322(5.482)$ & 6.99 & $\begin{array}{l}< \\
0.001\end{array}$ & $\begin{array}{l}35.598 \\
(6.150)\end{array}$ & 5.79 & $\begin{array}{l}< \\
0.001\end{array}$ & $\begin{array}{l}23.078 \\
(5.526)\end{array}$ & 4.18 & $\begin{array}{l}< \\
0 . c\end{array}$ \\
\hline $\mathrm{R}^{2}$ & $\mathrm{R}^{2}=0.167, \mathrm{~F}=1$ & $50, p<$ & .001 & $\mathrm{R} 2=0.334, \mathrm{~F}=$ & $8.68, p$ & 01 & $\mathrm{R}^{2}=0.430, \mathrm{~F}=$ & $7.98, \mathrm{p}$ & 0.001 & $\mathrm{R} 2=0.437, \mathrm{~F}=$ & 5.21, & .00 \\
\hline
\end{tabular}

\section{Figures}




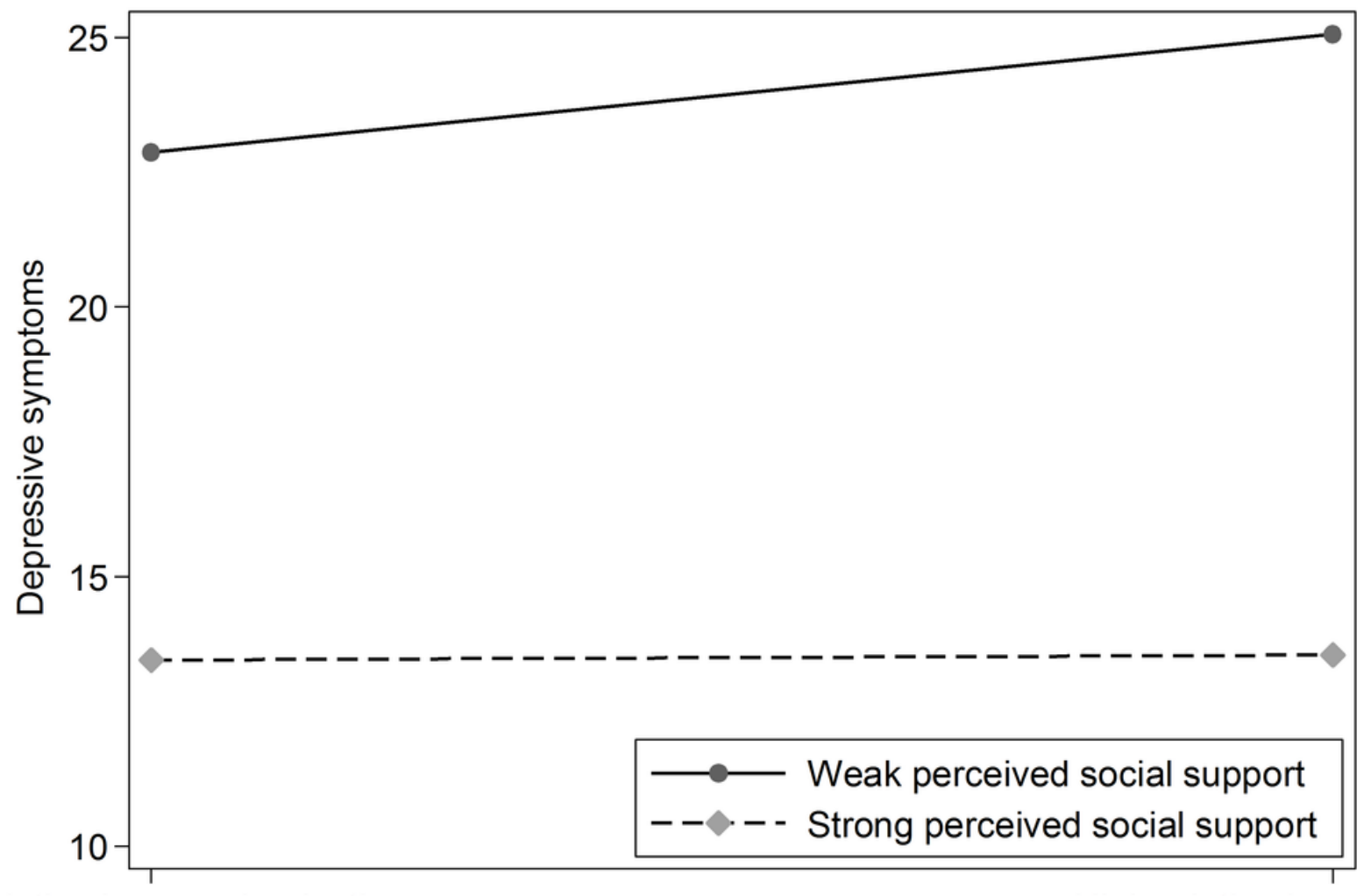

Low relative income deprivation

Relative income deprivation

High relative income deprivation

Figure 1

Perceived social support buffers subjective relative income deprivation 


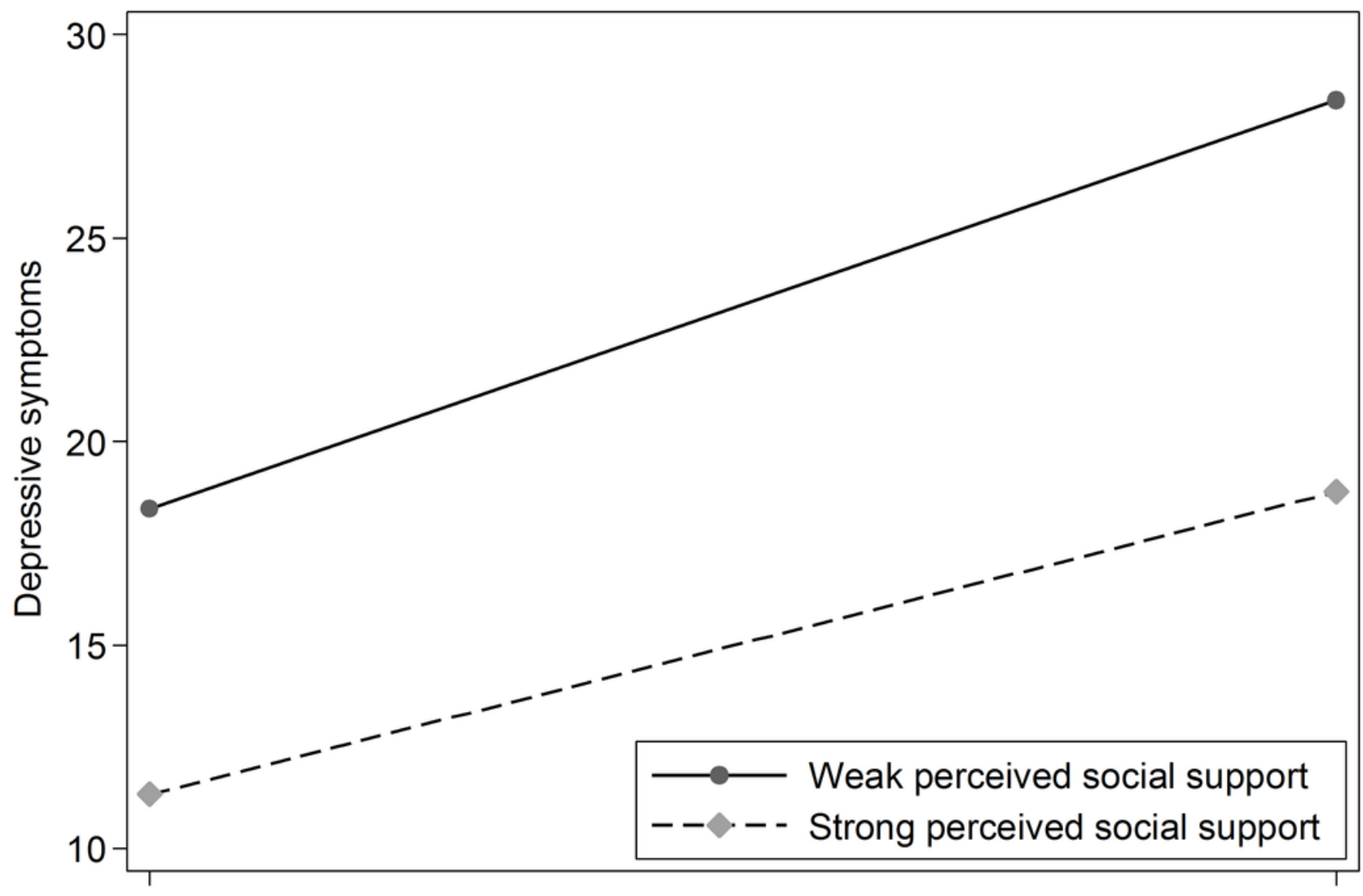

Low relative deprivation

Objective relative deprivation

Figure 2

Perceived social support buffers relative deprivation in psychological strain 